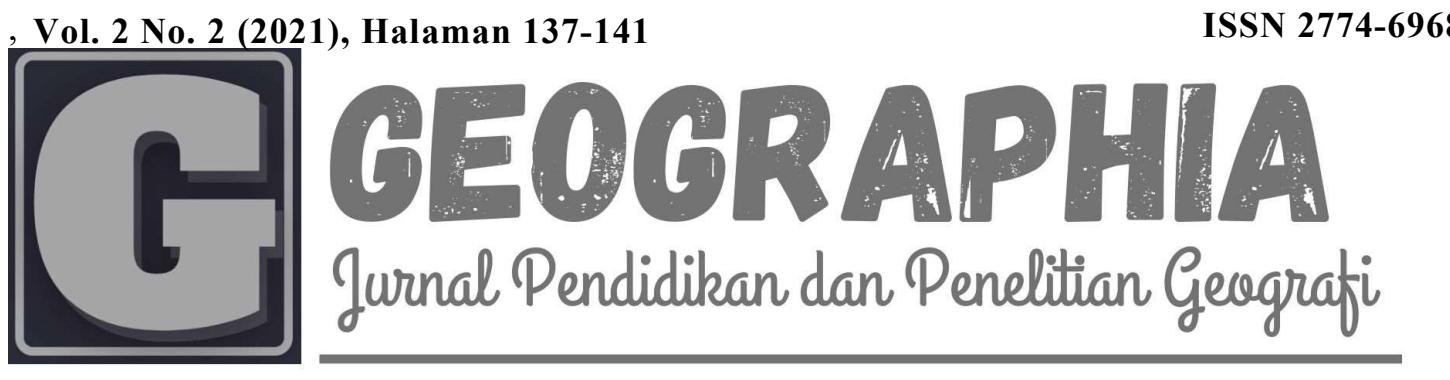

\title{
KAJIAN PENGEMBANGAN OBJEK AGROWISATA KACINAMBUNAN HIGHLAND PUNCAK 2000 SIOSAR KECAMATAN TIGAPANAH KABUPATEN KARO
}

\author{
Adi Permana Sinuhaji ${ }^{1}$, Fonny Rewah ${ }^{2}$, Kalvin Salindeho Andaria ${ }^{3}$ \\ ${ }^{1}$ Jurusan Pendidikan Geografi, Universitas Negeri Manado \\ Email: adisinuhaji17@gmail.com \\ ${ }^{2}$ Jurusan Pendidikan Geografi, Universitas Negeri Manado \\ Email: fonnyrewah@unima.ac.id \\ ${ }^{3}$ Jurusan Pendidikan Geografi, Universitas Negeri Manado \\ Email:kalvinsandaria@unima.ac.id
}

\begin{abstract}
Website Jurnal: http://ejurnal.unima.ac.id/index.php/geographia
(c)_(1) C Akses dibawah lisensi CC BY-SA $4.0 \mathrm{http}: / /$ creativecommons.org/licenses/by-sa/4.0/ DOI: $10.53682 /$ gjppg.v2i2.1966
\end{abstract}

(Diterima: 29-07-2021; Direvisi: 08-11-2021; Disetujui: 11-11-2021)

\begin{abstract}
The tourism sector today still relies on the use of coastal areas as objects. There needs to be a tourist attraction so that it is more diverse. The tourism sector is also expected to encourage other sectors such as the plantation, agriculture, trade, and industrial sectors. While in the agricultural sector is agrotourism. Therefore, it is necessary to study the development of agro-tourism objects, especially Agrotourism in the Kacinambun Highlands, Puncak 2000, Siosar, Kacinambun Village, Tigapanah District, Karo Regency, North Sumatra. The focus of the research is the study of development factors with subfocuses, namely: 1) attractiveness conditions, 2) accessibility conditions, 3) facilities and infrastructure conditions, 3) promotion conditions, and 4) visiting conditions. The research method used is descriptive qualitative. The results of the study show, 1) the attraction is the beautiful nature offered by the charm and views of the community's plantations, 2) easy accessibility, positioning strategies, transportation networks are still minimal, 3) facilities and infrastructure are already supportive and available both complementary infrastructure, supporting infrastructure, and public infrastructure but not yet maximized. 4) tourism promotion utilizes social media, magazines, and daily newspapers to provide information to potential tourists, and 5) efforts to increase visits are carried out by developing attractions, facilities and also utilizing natural beauty such as community agricultural plants with multicultural types of plants to be shown to tourists.
\end{abstract}

Keywords: Agrotourism, Study, Development.

\section{ABSTRAK}

Sektor pariwisata dewasa ini masih bertumpu pada pemanfaatan kawasan pesisir sebagai objek. Perlu adanya diversifikasi objek wisata sehingga lebih beragam. Sektor pariwisata juga diharapkan mendorong pertumbuhan sektor lain seperti sektor perkebunan, pertanian, perdagangan, dan perindustrian. Sementara dalam sektor pertanian, adalah agrowisata (agrotourism). Oleh karena itu perlu adanya kajian pengembangan objek agrowisata khususnya Objek Agrowisata Kacinambun Highland Puncak 2000 Siosar Desa Kacinambun Kecamatan Tigapanah Kabupaten Karo Sumatra Utara tujuan penelitian ini. Fokus penelitian adalah kajian faktor pengembangan dengan subfokus 
yaitu: 1) kondisi daya tarik, 2) kondisi aksesibilitas, 3) kondisi sarana dan prasarana, 3) kondisi promosi, dan 4) kondisi kunjungan. Metode penelitian yang digunakan yaitu deskriptif kualitatif. Hasil penelitian menunjukkan, 1) daya tarik adalah alam yang indah yang ditawarkan oleh pesona dan hamparan perkebunan masyarakat, 2) aksesibilitas mudah diakses, posisi strategis, jaringan transportasi masih minim, 3) sarana dan prasarana sudah mendukung dan tersedia baik itu prasarana pelengkap, prasarana penunjang, dan prasarana umum namun belum maksimal. 4) promosi wisata memanfaatkan media sosial, majalah dan koran harian untuk memberikan informasi kepada calon wisatawan, dan 5) usaha peningkatan kunjungan dilakukan dengan pengembangan wahana atraksi, fasilitas dan juga memanfaatkan keindahan alam seperti hamparan tanaman pertanian masyarakat dengan jenis tanaman yang multikultural untuk diperlihatkan kepada wisatawan.

Kata Kunci: Agrowisata, Kajian, Pengembangan

\section{PENDAHULUAN}

Sektor pariwisata memiliki peluang pemicu pertumbuhan ekonomi. Sektor pariwisata juga diharapkan mendorong pertumbuhan sektor lain seperti sektor perkebunan, pertanian, perdagangan, dan perindustrian. Sementara dalam sektor pertanian, adalah agrowisata (agrotourism). Sektor pariwisata dewasa ini masih bertumpu pada pemanfaatan kawasan pesisir sebagai objek. Perlu adanya diversifikasi objek wisata sehingga lebih beragam. Pelibatan masyarakat pun diperlukan dalam pengembangan objek wisata ini. Proses pelibatan mayarakat dimulai sejak tahap perencanaan, pengelolaan, dan pengembangan.

Agrowisata merupakan rangkaian kegiatan wisata dengan pelibatan potensi lahan pertanian, kawasan pertanian, aktivitas produksi, dan budaya masyarakat pertanian (Tjahjono et al., 2018). Agrowisata merupakan kombinasi pertanian dan pariwisata (Kristiana dan Nathalia, 2021). Sasaran dan fokus utama agrowisata adalah objek dan atraksi aktivitas pertanian. Pelibatan masyarakat diperlukan untuk perlindungan sumber daya dan atraksi, fasilitas dan infrastruktur (Andaria et al., 2018).

Kajian yang dapat dilakukan dalam konsep pengembangan objek agrowisata adalah daya tarik, aksesibilitas, sarana dan prasarana, promosi, dan kunjungan. Beberapa aspek yang diperlukan dalam perencanaan dan pengembangan agrowisata adalah karakteristik wisatawan seperti usia, pekerjaan, dan kesukaan. Aspek transportasi berkaitan dengan ketesediaan, dan jenis kendaraan yang digunakan. Aspek atraksi berkaitan aktivitas yang disediakan dan difasilitasi dalam bentuk apa yang dilihat, dilakukan, dan dibeli. Aspek pelayanan berkaitan dengan fasilitas penunjang kegiatan wisata. Aspek informasi berkaitan cara memperoleh informasi daya tarik wisata.

Daya tarik wisata dapat dijelaskan sebagai keunikan, nilai keanekaragaman kekayaan alam, budaya, dan hasil buatan manusia yang menjadi sasaran kunjungan wisatawan. Hal tersebut yang menjadi daya tarik bagi orang mengunjungi suatu daerah (Oka, 1996; Pendit, 2002; Setzer, 2016). Selain daya tarik wisata aspek lainnya adalah jaringan transportasi. Objek wisata harus memenuhi aksesibilitas, yaitu mudah tempat wisata mudah dicapai dan ditemukan berupa kemudahan jalan (Abdulhaji dan Yusuf, 2017).

Berkaitan dengan hubungan usaha objek wisata untuk menarik wisatawan, lebih lama tinggal, dan mengeluarkan banyak uang maka sarana dan prasana berperan penting. Sarana tersebut berkaitan dengan sarana pokok pelayanan kegiatan wisata. Sarana perjalanan dan penyelenggaraan tour memudahkan wisatawan sampai di lokasi. Pelayanan penginapan dan pelayanan makanan serta minuman memudahkan pemenuhan pokok wisatawan selama di lokasi wisata. Sarana pelengkap, penungjang, dan prasarana umum dibangun sedemikian rupa, sehingga fungsinya dapat membuat wisatawan lebih lama tinggal di tempat wisata.

Kegiatan promosi diperlukan sebagai sarana memberikan informasi, membujuk dan mempengaruhi, serta menciptakan kesan baik sebagai upaya mencapai tujuan menciptakan pertukaran sehingga keinginan wisatawan terpenuhi (Abdulhaji dan Yusuf, 2017). Wisatawan adalah konsumen atau pengguna produk dan layanan wisata. Perubahanperubahan yang terjadi pada kehidupannya berdampak pada kebutuhan wisata, dalam hal ini permintaan wisata. Banyak wisatawan yang berkunjung menjadikan sektor pariwisata 
berpotensi meningkatkan pendapatan asli daerah (Purwanti, 2014).

Berkaitan dengan potensi agrowisata di kabupaten Karo adalah kawasan objek argowisata Kacinanbunan Highland Puncak 2000 Siosar. Daya tarik dari objek agrowisata ini adalah wisata petik buah, labirin jagung, dan memberi makan hewan ternak. Semenjak erupsi Gunung Sinabung tahun 2013, kawasan Siosar menjadi tempat relokasi pengungsi dengan mengubah area hutan menjadi permukiman penduduk yang membentang dari kecamatan Tigapanah dan kecamatan Merek. Dengan adanya pengembangan argowisata ini penduduk diarahkan yang semula bergerak dibidang pertanian, juga diarahkan menuju sektor wisata. Kegiatan agrowisata ini diharapkan berdampak pada peningkatan ekonomi masyarakat di sekitar kawasan (Charles, 2019). Oleh karena itu penulis memandang perlu untuk mengadakan penelitian tentang kajian pengembangan objek agrowisata Kacinambun Highland Puncak 2000 Siosar Desa Kacinambun Kecamatan Tigapanah Kabupaten Karo Sumatera Utara.

\section{METODE PENELITIAN}

Metode penelitian yang digunakan yaitu metode deskriptif kualitatif. Subfokus penelitian terdiri dari 1) kondisi daya tarik, 2) kondisi aksesibilitas, 3) kondisi sarana dan prasarana, 4) kondisi promosi, dan 5) kondisi kunjungan. Penentuan informan sebagai ditentukan dengan teknik snowball sampling. Teknik pengumpulan dengan observasi, wawancara, dan dokumentasi. Teknik analisis data dengan tahapan pengumpulan data, reduksi data, penyajian, dan penarikan kesimpulan (Sugiyono, 2016). Uji keabsahan data dilakukan dengan uji kredibilitas, uji transferabilitas, uji dependabilitas, dan uji konfirmabilitas.

\section{HASIL PENELITIAN DAN PEMBAHASAN}

Lokasi Penelitian

Penelitian dilaksanakan di perbukitan objek agrowisata Kacinambun Highland Puncak 2000 Siosar terletak di Desa Kacinambun Kecamatan Tigapanah Kabupaten Karo Provinsi Sumatra Utara. Luas desa adalah $8 \mathrm{~km}^{2}$ dengan tinggi wilayahnya $1.750 \mathrm{dpal}$. Lokasi penelitian dapat dilihat pada Gambar 1.

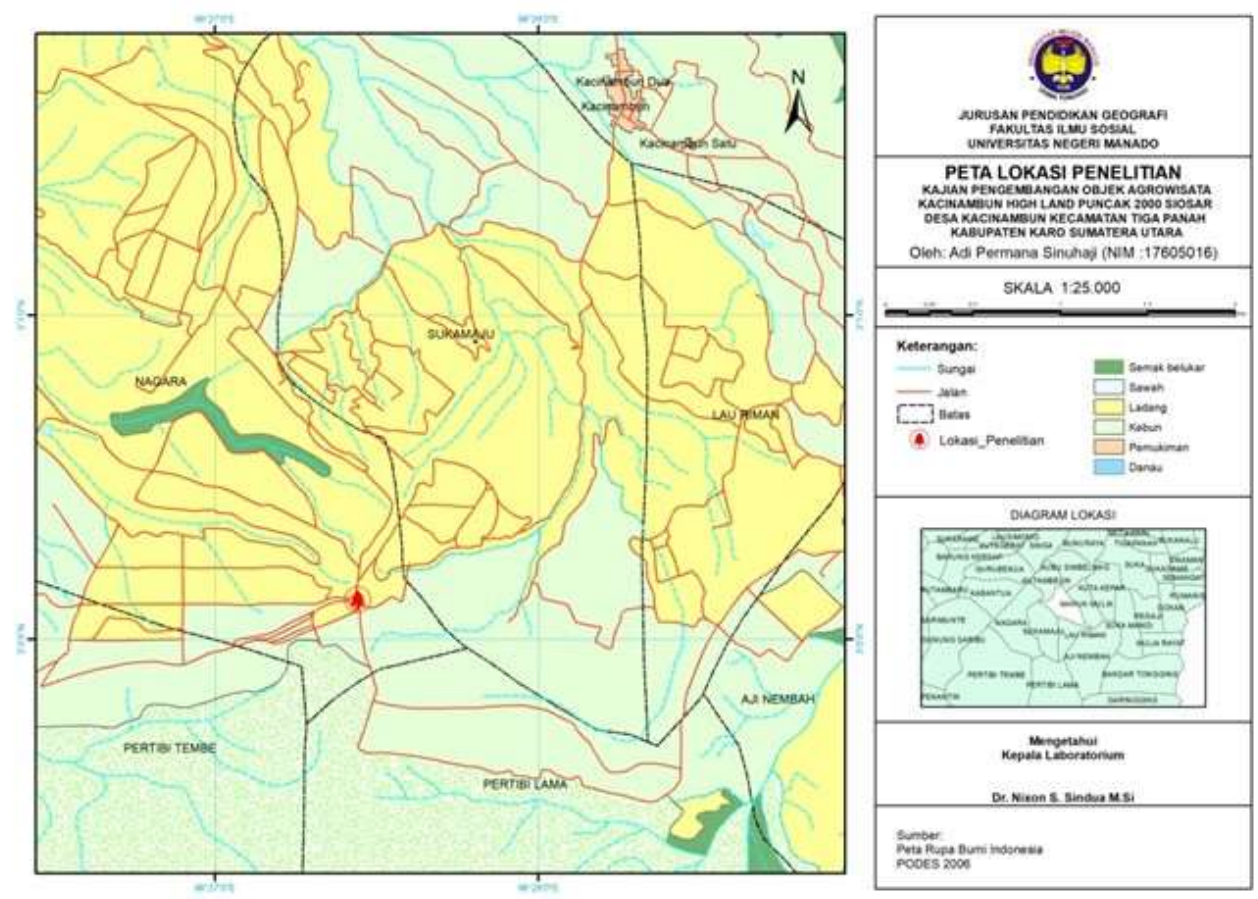

Gambar 1.

Lokasi Penelitian 


\section{Daya Tarik Objek Agrowisata}

Daya tarik wisata berkaitan dengan keunikan, dan nilai keanekaragaman kekayaan alam. Faktor-faktor sebagai daya tarik adalah keindahan alam dan jenis tanaman yang beragam, seperti kebun jeruk yang dapat dipetik sendiri. Alam indah yang ditawarkan oleh pesona dan hamparan keindahaan jenis-jenis masyarakat merupakan kekuatan dan daya tarik yang menarik perhatian dengan nilai tinggi untuk dikunjungi dan dilihat oleh wisatawan yang berkunjung ke objek wista tersebut. Hasil penelitian tersebut sesuai dengan pandangan dalam kajian teori Setzer (2016) bahwa daya tarik wisata adalah segala sesuatu yang mempunyai daya tarik, keunikan dan nilai yang tinggi, yang menjadi tujuan wisatawan datang ke suatu daerah tertentu.

\section{Aksesibilitas Objek Agrowisata}

Aksesibilitas objek agrowisata berkaitan dengan kemudahan mencapai lokasi wisata. Faktor-faktor yang memengaruhi aksesibilitas adalah mudah dilalui dan jalan sudah beraspal. Kondisi akses jalan bagus dan mudah dilalui oleh jaringan transportasi baik kendaraan pribadi dan kendaraan umum. Artinya objek wisata mudah dilalui dan dengan sendirinya juga mudah ditemukan. Namun untuk keadaan jaringan transportasi diketahui angkutan umum sangat minim dan hanya ada dalam waktu (jam) tertentu saja dan pengunjung lebih banyak menggunakan kendaraan pribadi mereka masing-masing.

Hasil penelitian tersebut sesuai dengan pandangan dalam kajian Abdulhaji dan Yusuf (2017) bahwa persyaratan aksesibilitas terdiri dari akses informasi dimana fasilitas harus mudah ditemukan dan mudah dicapai, harus memiliki akses kondisi jalan yang dapat dilalui dan sampai ke tempat obyek wisata. Jarak lokasi mudah diakses dan memiliki posisi yang strategis karana dekat dengan pusat kota Kabanjahe dengan lama waktu tempuh 30 menit perjalanan. Sarana kepariwisataan, jalan termasuk yang lainnya saling melengkapi pada kegiatan wisata.

\section{Sarana dan Prasarana Objek Agrowisata}

Objek agrowisata kurang maksimal. Pengelolaan sampah perlu ditata oleh pihak pengelola maupun oleh masyarakat setempat.
Sarana dan Prasarananya sudah sangat mendukung dan tersedia baik itu di prasrana pelengkap, prasarana penunjang dan prasarana umum.

Hasil penelitian tersebut sesuai dengan pandangan dalam kajian Abdulhaji dan Yusuf (2017) bahwa sarana pelengkap kepariwisataan (supplementing tourism superstructure), yaitu sarana yang dapat melengkapi sarana pokok sedemikian rupa, sehingga fungsinya dapat membuat wisatawan lebih lama tinggal di tempat atau di daerah yang dikunjunginya. Sarana penunjang kepariwisataan (supporting tourism superstructure), adalah fasilitas yang diperlukan wisatawan (khususnya business tourist), yang berfungsi tidak hanya melengkapi sarana pokok dan sarana pelengkap, tetapi fungsinya lebih penting adalah agar wisatawan lebih banyak membelanjakan uangnya di tempat yang di kunjunginya tersebut. Prasarana umum, terdiri dari jaringan jalan raya, jembatan, transportasi laut, darat, dan udara, serta prasarana lain yang terdiri dari sistem penyediaan air bersih, pembangkit tenaga listrik, fasilitas telekomunikasi, kantor pos, rumah sakit, pompa bensin, dan apotek promosi.

\section{Promosi Objek Agrowisata}

Masyarakat maupun pengelola memanfaatkan media sosial, majalah dan koran harian untuk memberikan informasi kepada calon wisatawan. Hasil penelitian tersebut sesuai dengan pandangan dalam kajian Abdulhaji dan Yusuf (2017) bahwa promosi dapat digunakan untuk mencapai tujuan yakni untuk menciptakan pertukaran yang menguntungkan melalui komunikasi, sehingga keinginan wistawan dapat terpenuhi. Dalam hal ini komunikasi dapat menunjukkan cara-cara untuk mengadakan pertukaran yang saling memuaskan.

\section{Kunjungan Wisatawan}

Upaya peningkatkan kunjungan wisatwan dilakukan melalui cara pengembangan wahana atraksi, fasilitas dan juga memanfaatkan keindahan alam seperti hamparan tanaman pertanian masyarakat dengan jenis tanaman yang multikultural untuk diperlihatkan kepada wisatawan. Hasil penelitian tersebut sesuai dengan pandangan dalam kajian Purwanti (2014) bahwa pengaruh kunjungan wisatawan sangat berarti untuk 
pengembangan industri pariwisata dan pendapatan asli daerah sehingga wisatawan domestik maupun wisatawan mancanegara tertarik untuk berkunjung diantaranya atraksi merupakan salah satu komponen pertama dalam menarik wisatawan untuk berwisata ke suatu daerah. Jarak yang ditempuh atau aksesibilitas memberikan kemudahan bagi wisatwan untuk berkunjung ke tempat wisata, tingkat usia, biaya perjalanan, keindahan alam, fasilitas, dan biaya masuk.

\section{KESIMPULAN}

Daya tarik bagi objek ini adalah alam yang indah yang ditawarkan oleh pesona dan hamparan keindahaan jenis-jenis kebun masyarakat. Aksesibilitas terkait kondisi akses jalan baik dan mudah dilalui oleh jaringan transportasi. Namun untuk keadaan jaringan transportasi masih sangat minim. Jarak yang ditempuh mudah diakses, posisi yang strategis, dan dekat dengan pusat kota. Sarana dan prasarana sudah mendukung dan tersedia baik itu prasarana pelengkap, prasarana penunjang, dan prasarana umum namun belum maksimal. Promosi objek agrowisata memanfaatkan media sosial, majalah dan koran harian untuk memberikan informasi kepada calon wisatawan. Peningkatan kunjungan wisatawan dilakukan dengan pengembangan wahana atraksi, fasilitas dan juga memanfaatkan keindahan alam seperti hamparan tanaman pertanian masyarakat dengan jenis tanaman yang multikultural untuk diperlihatkan kepada wisatawan.

\section{SARAN}

Pengelola yang ada di objek agrowisata seharusnya mempercepat proses pengembangan seperti fasilitas yang masih dalam masa pembangunan agar sisa-sisa material tidak merusak daya tarik wisata bagi pengunjung. Masyarakat hendaknya membuat rute perjalanan atau jasa angkutan umum untuk memudahkan jaringan transportasi yang saat ini masih minim atau kurang untuk proses pengembangan objek agrowisata.

\section{DAFTAR PUSTAKA}

Abdulhaji, S., \& Yusuf, I. S. H. 2017. Pengaruh Atraksi, Aksesibilitas dan Fasilitas terhadap Citra Objek Wisata Danau Tolire
Besar di Kota Ternate. Humano: Jurnal Penelitian, 7(2), 134148.https://doi.org/http://dx.doi.org/10.33 387/hjp.v7i2.317

Andaria, K. S., Sendouw, R. H. E., Lonto, A. L., Lobja, X. E., \& Sindua, N. J. 2018. Identification of Potential Tourism in East Likupang Subdistrict Bangka Island North Minahasa. 1st International Conference on Social Sciences (ICSS 2018), 742-746.

Charles. 2019. Siosar Akan dijadikan Wilayah Agrowisata, Ini Pertimbangan Gubsu. https://www.hetanews.com/article/14850 8/siosar-akan-dijadikan-wilayahagrowisata-ini-pertimbangan-gubsu

Kristiana, Y., \& Nathalia, T. C. 2021. Identifikasi Manfaat Ekonomi untuk Masyarakat Lokal dalam Penerapan Pariwisata Berkelanjutan di Desa Wisata Kereng Bangkirai. Jurnal Akademi Pariwisata Medan, 9(2), 145-153.

Oka, A. Y. 1996. Pengantar Ilmu Pariwisata. Bandung: Angkasa.

Pendit, N. S. 2002. Ilmu Pariwisata. Jakarta: Pradnya Paramita.

Purwanti, N. D. 2014. Pengaruh Jumlah Kunjungan Wisatawan Terhadap Pendapatan Asli Daerah Kabupaten Mojokerto Tahun 2006-2013. Jurnal Pendidikan Ekonomi (JUPE), 2(3). https://doi.org/https://doi.org/10.26740/ju pe.v2n3.p $\% 25 p$

Setzer, M. 2016. Definisi Daya Tarik Wisata. http://pariwisatadanteknologi.blogspot.co $\mathrm{m} / 2010 / 07 /$ definisi-daya-tarikwisata.html

Sugiyono. 2016. Memahami Penelitian Kualitatif. Bandung: Alfabeta.

Tjahjono, J. D., Sasongko, P. E., \& Arifin, A. Z. 2018. Kebijakan dan Strategi Pengembangan Kawasan Agroekowisata Kecamatan Tuturdi Kabupaten Pasuruan. Peduli, 2(1), 32-39. 